\title{
Erratum to: Thoracic splenosis: know it-avoid unnecessary investigations, interventions, and thoracotomy
}

\author{
Amir Maqbul Khan, MD · Kamran Manzoor, MD \\ Zeeshan Malik, BSc • Yasim Avsar, MD \\ Chang Shim, MD
}

(C) The Japanese Association for Thoracic Surgery 2011

Erratum to: Gen Thorac Cardiovasc Surg (2011) 59:245-253 DOI 10.1007/s11748-010-0706-8

The 4th author's name appeared incorrectly in the article cited above.

The author's name should have been shown as follows:

Yesim Avsar

This online version of the original article can be found at http://dx.doi.org/10.1007/s11748-010-0706-8.

A.M. Khan $(\bowtie)^{1} \cdot$ K. Manzoor $\cdot$ Z. Malik · Y. Avsar .

C. Shim

Department of Pulmonary Medicine, Montefiore Medical

Center, Albert Einstein College of Medicine, Bronx, NY, USA

Tel. +1-903-504-5594; Fax +1-903-934-5461

e-mail: dramirkhan@hotmail.com

Present address:

${ }^{1} 150$ Timber Falls Drive, Longview, TX 75605, USA 